\title{
Surging virtual reference services COVID-19 a game changer
}

n March 2020, academic libraries across the

United States closed and sent everyone home, some destined to not reopen for months. University offices closed. Classes were moved online. Suddenly, librarians and staff pivoted to working from home and to all remote services, without time for planning logistics or training. To study the impact of this extraordinary and sweeping transition on virtual reference services (VRS), we conducted a major study of academic library responses to the pandemic that focused on librarian perceptions of how services and relationships with users morphed during this COVID-19 year.

Academic librarians rallied to our call, and we collected a total of 300 responses to two longitudinal surveys launched at key points during the pandemic. Data collection focused on two phases in 2020: 1) shutdown and immediate aftermath (mid-March to July), and 2) fall ramp up and into the semester (August to December). Via Zoom, we also interviewed 28 academic librarian leaders (e.g., heads of reference and/or VRS, associate directors for User Services) from September to November. Surveys and interviews centered on adaptations and innovations to reference services, especially VRS and perceptions of changes in user interactions.

\section{Sneak peek at our results}

So, what did we find? Librarians are resilient and creative professionals. Participants shared many successes over time, although there were also bumps (and some boulders) along the way. Overall, librarians were well-prepared for the transition to online-only reference and instruction, and they also stepped up as change agents offering ground- breaking services to help students adjust to the "next normal" of online learning and the gradual return as library buildings slowly and/or partially reopened during the fall semester.

\section{The only game in town: Online services}

Most participants reported that VRS was in place pre-COVID, including live chat, email, and online information literacy instruction (ILI). Some institutions had already zoomed to online video reference consults. When campuses closed and instruction moved online, VRS transformed into the premier essential user service. For most, preCOVID VRS had accompanied face-to-face reference, with some stating that VRS were not well known and underused. Those few without VRS in place scrambled to start them in the wake of campus closures, and soon discovered their value. However, it quickly became apparent, especially for live chat, that in ramping up to accommodate increased demand, librarians and staff required additional training in systems, sources, and procedures, including assessment. Website updates also became urgent. The large majority

Marie L. Radford is chair and professor of the Department of Library and Information Science at Rutgers, the State University of New Jersey, email: mradford@rutgers.edu, Laura Costello is virtual reference services librarian at Rutgers University Libraries and a doctoral student at Rutgers University, email: laura.costello@rutgers.edu, and Kaitlin Montague is a doctoral student at Rutgers University, email: kaitlin.montague@rutgers.edu 
of participants who had established VRS were able to seamlessly pivot to online-only service, reporting that usage skyrocketed in the early days of the pandemic. As some buildings reopen, respondents comment that many students remain more comfortable with chat/email than to coming in, despite diligent cleaning, oceans of hand sanitizer, and social distancing measures.

\section{VRS to the rescue}

Including data from both surveys, $71 \%$ of our 300 respondents reported rising trends, with higher or steady volume for VRS live chat. Participants observed that, while students and faculty were stressed about teaching and learning online, they were generally more polite, appreciative, and patient with changing services. One survey participant suggested that during the pandemic, "There is a greater need for academic support. I think it is a need for 'human' support as well." Anxieties centered on inability to access print resources, especially book reserves, and lack of experience with online learning platforms (for students and faculty). Initially, interlibrary loan was disabled while print/media collections were inaccessible. Electronic collections, like Hathi Trust, were used as stopgaps, but such collections are incomplete, and accessible by members only.

In early days, students worried about accruing overdue fines. Some became impatient, even rude, and many participants reported "dropped" chats and disappearing users. Librarians expressed compassion for stressed-out students and faculty, although patience was frayed at times, as participants recognized that they, as well as their library colleagues, were also deeply stressed by the pandemic. Cultivating positive interpersonal interactions are always critically important for reference success, the good news was that negative encounters were the exception. Many users felt and expressed gratitude that librarians and staff continued to provide VRS during institutional closures.

\section{Libraries = university online}

We could have predicted that academic libraries were well-positioned to move operations online at short notice, but what about other university offices and services, such as academic advising, financial offices, etc.? Because so many libraries were already offering live chat VRS, they hit the ground running. Participants reported questions dealing with the wider university or with external requests greatly increased during the pandemic. Library profiles were raised within institutions as librarians responded to fill the gap of shuttered offices. One participant indicated that after their campus closure, the university administration asked them to provide an institutional information service, providing guidance for students in navigating all university queries. This led to a shift in VRS question topics, with uptick for directions, referrals, and procedures. On the other hand, especially as the fall semester progressed, many reported a change in question complexity with more research-type or multipart questions being received in chat.

\section{Transformation-radical shifts}

The pandemic caused seismic-level shifts in library priorities and realities, in where we work, when we work, the way we work, and what we do. It could be argued that COVID-19 prompted an upheaval in academic libraries whose magnitude is unequaled in modern times, except perhaps for the advent of the Web in the early 1990s. In the move to telework, participants highlighted challenges in life-work balance. Many juggled work with childcare needs as schools remained closed, moving K-12 instruction online. Chat service hours were expanded, and new affordances, such as widgets and screen sharing, were initiated. Innovative services, such as video chat or Zoom drop-in reference hours were launched. Some had strong take-up, some fizzled, some were abandoned, some were tweaked and relaunched. Budgets tightened. Some librarians retired, and positions were left vacant. Other universities downsized staff. Often staff faced a pressing need to update their skillset, to master unfamiliar communication, ILI, and/or VRS systems. Change management strategies included reorganized library units and teams, uptake of an array of internal and external communication platforms (e.g., Slack, Teams, Google Voice), forging partnerships across the library and university, crosstraining staff, and greater collaboration/transpar-

(continues on page 113) 
me-my mannerisms, my walk maybe, the way I spoke to the waitress? Will they regret hiring me? Will I wish for these sterile black-and-white ultra-polite relationships a year from now, when his boisterous laugh or her tedious cat stories irk me? I think not. I miss people.

Working during this pandemic shows us a different side of people. It undoubtedly makes everything more professional and productive. Yet, it is less human. Won't it be interesting to see which of my co-workers will make me laugh in person after this strange delay? Who will end up becoming a good friend, who will become my professional nemesis? I will continue to be held in some suspense for these answers. It is a bit like that old show The Dating Game, where contestants were prevented from seeing each other while they tried to determine who would be compatible on a date simply by talking to each other. I am looking forward to the big post-Zoom reveal. I cannot wait.

For the foreseeable future, I am not allowed to be physically near my new colleagues. We are limited to the plane in which we are currently working. Vaccines have been approved, so both the benefits and the drawbacks of these peculiar and unique circumstances will likely not be re- peated. I wonder what I will miss about working from my apartment, literally half-dressed all day. What will I wish I could maintain from my virtual environment? I suspect the answer is probably nothing at all.

I believe every academic librarian prefers being on a college campus, where the atmosphere is bustling with students and energy. Being sequestered at home has brought to light just how much that backdrop for being a librarian means to me. College campuses are usually lively, exciting environments. They are ever-changing communities, bursting with innovation and challenges to the status quo.

After six months I do not feel like a genuine part of my new community. I am still an outsider, watching it on my computer screen. I see photos of a past life all over my university's website. There are images of smiling unmasked students, laughing with their arms around each other, blissfully unaware of what is coming.

One thing this terrible pandemic has taught us is that we are much more social than many of us thought. It has been hard on everybody not to be together. Innumerable subtleties are missed. I hope I never take the human minutiae for granted again. Bring on the cat stories.

\section{("Surging virtual reference services," continued from page 107)}

ency among departments, including circulation and reference. Additionally, there was an urgent priority for electronic access and a greater focus on copyright and open access issues, especially driven by requests from faculty transitioning courses online and students requesting more ebooks, including e-textbooks (especially in community college libraries).

The pandemic sharpened focus on our core strengths of providing excellent and equitable service to all users, and pushing increased access to high-quality, reliable information to combat misinformation and disinformation, especially during crisis. Our research serves immediate, future, and historical purposes, helping librarians to: a) continue adapting to the ongoing pandemic, b) build resilience to respond to any unforeseen disruptions or crises, and c) serve as a record of the incredible academic librarian response to ensure that their users and institutions would move ahead, even as the world shut down. Our research has overwhelmingly shown that amid the confusion of institutional closures, librarians led their campuses in uninterrupted service to their communities. As one participant said, "I think that one of the big value-added things about librarians is creating connections and a sense of belonging." How much will all these game changes that COVID-19 hath wrought continue? This remains to be seen, and much hinges on our professional vision, decisions, values, and will. Service excellence is an individual choice, made in the midst of every encounter.

As we continue our analysis, stay tuned for future presentations and publications. We invite you to our ACRL 2021 Virtual Conference panel presentation "Taking the Temperature: Research in the Time of COVID-19" for updated results on library research in the pandemic. $\boldsymbol{n}$ 